fond jet another anes for the gemenal paralyois of the frane- one located not in the meninges, as Bayle teaches es, nor in the cortical substance of the brain, as Calmeil acearts, but in the medullary (fibrous) or white substance of the cerebral mass. This, he sajs, is indurated in all caces of mania, complicated with general paralysis. "Each cenebral fibre has contracted morbid adhesions with the currounding fibres, 20 as to render their separation imposaivle." Buch are his words.

Drs. Prichard and Hitchman, and Mr. Solly, advocate a very similar doctrine to that insisted on by Foville, in so far as the changes in the grey or cortical substance are concerned. Thus, the first named has given it as his opinion, that a softness of the cortical substance belongs to cases of the last degree of dementia, with general paralysis; and that, in all such cases, its colour is more brown than usual. The second writer insists, and very properly 80, that inanity is essentially dependent upon " some change or irritation produced in the vesicular neurine of the convolutions of the brain; and that that malady is influenced by the ame laws, and dependent on like physical changes of material structure, as are diseases of the lungs or any other viscera." He adds, moreover, "that in every case of acute othenic manis there is an inflamed condition of that structure; and that the convolutions, if seen, would present a roseate hue." Mr. Bolly, at p. 400 et seq. of his great work On the Brain, has these words: "We cannot, of course, ascribe the mental disturbance, excitement, excessive pain, intolerance of light, delirium, and insanity, which we have observed as the diagnostic marks of inflammation of the arachnoid and pia mater, to simple lesion of either a serous or rascular membrane, we are compelted to refer them all to the injury which that portion of the brain in contact with those membranes must have reeeived from the disturbance of its circulation. Hence it reasonably follows, that the hemispherical ganglia (brain) are intimately connected with the intellectual powers, and that it is in them peculiarly, and not in the whole cerebral mass, that these powers reside; in fact, as before stated, that the medullary substance benesth is, in all probability, merely the passive servant, as it were, of the cineritious, either as the conductor of its commands to the muscles, or of the materials, namely, the various impressions made on the peripheral extremities of the nerves of sense, which the cineritious perceives, and with which it works."

The reciprocity of action, both normal and abnormal, between the meninges and the cerebral substance is, as Mr. Bolly observes, much insisted on by many eminent men, including Pinel, Bouilland, and Lallemand. The last named writes: "The substance of the brain is irritated by an inflammation of the arachnoid, from its vicinity, and its functions are therefore exalted; and consequently those of the nervous system under its dependence and consequently those also of the muscular system: and from hence arise convulsive movements, etc. But, as the tissue of the brain is not yet destroyed, these symptoms are neither accompanied with nor followed by paralysis." The few following words are from the Principles of Medicine, by Dr. Billing: "But although, upon a careful analysis of the symptoms and the different forms of the neuroses, we may, with attention to physiology, refer some to an affection of the cineritious, and others of the medullary parts of the nervous system, we should, a priori, from our knowledge of the conmexion and mutual cooperation of these two divisions of the nervous system, expect to meet with disease depending upon eimultaneous disturbance in both. Thus, from the violent operation of sedatives, or when an animal is bled to death, the first to suffer is the most vascular-i.e. the seereting and the sensorial part, the cineritious substance; hemee the indistinctness of the perceptions and thoughts, and the weakness of the involuntary and voluntary actions. If the operation of the sedative be increased, or the analogoes injury of further loss of blood take place, the medulwo part of the nervous system evinces its effect by general epenodic muscular contractions."

I lare alreads wtated that, secording to Foville and D
Hitchman, in caces of scute manis, " the grey matter of the brain is found of a most intense redness, approaching to that of erysipelas", or "injected, and of a roseate hue". Mr. Solly, however, is found to declare the same structure to present, and in the same disorder (mania), "a dark plum colour". Further even than this, I have the notes of the post mortem examination of $\mathbf{M}$. A. (a patient of the Hanwell asylum in 1842, and who died there under my care, during a paroxysm of acute mania), in whom Dr. Conolly has roported that " the cineritious substance was generally very. pale".

But for these, and not less the foregoing contradictions, to which I have had occasion to refer, I shall hope, in my next lecture, to offer a most satisfactory explanation; and likewise to render the same the means of demonstrating, in the most conclusive manner, the bond fide nature and seat of mental derangement in all its various phases.

Northwoods, Bristol, August 1855

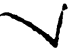

\section{THE MODERN TREATMENT OF} FRACTURES.

By BENJAMIN HUNT, Esq., Surgeon to the General Dispensary, Birmingham; late Resident Surgeon to the Queen's Hospital.

[Concluded from page 701.]

CASE XXX. H. R., aged 25 years, was taken to the Queen's Hospital on the 7th of January, 1853, in consequence of having suffered a comminuted fracture of his right leg, with a lacerated wound of the integument, from the wheel of 2 fire-engine passing over it.

I did not see the patient until the 22nd of February, six weeks after the receipt of the injury. The condition of the limb was then as follows: the tibia was broken obliquely from above downwards, and behind forwards; about an inch of the lower extremity of the upper fragment projected through a wound in the integument, and was necrosed; the leg was much shortened and deformed, being bowed anteriorly, and the heel depressed, viewed laterally; the wound was on the inner and anterior surface, about four inches above the ankle; it discharged pus in large quantities, and the parts about were much thickened.

The patient himself had suffered very much from pain, and wore an anxious expression on his face. The treatment that had been adopted consisted in supporting the foot and leg by well padded lateral splints, which reached to the knee; but they were inadequate for their purpose; every movement the man made allowed the fragments to ride one upon the other, causing pain, and keeping up irritation. To obviate these drawbacks to union, the limb was placed upon M'Intyre's splint, and kept carefully bandaged to it for three weeks, with much ease to the patient, and affording facility of dressing the wound; but, at the expiration of this period, the man complained of his back becoming sore, and also of the heel: symptoms of hectic began to show themselres, so that fear of sinking, from long confinement to bed, was entertained. Amputation of the limb seemed to be almost the only procedure by which his life could be saved.

Under these circumstances, I applied the apparatus so as to include the foot, leg, and half the thigh, in an extended position, as one mass ; and, on the following day, I made an opening in the case opposite the wound, for the escape of pus, and the employment of dressings; the object being to afford a complete support to the broken leg, so that he might leave his bed, and benefit by the change of posture, without disturbance to the fractured ends of the bone. In this I did not succeed in the first instance, because of the weakness of the apparatus, which did not give sufficient support to the limb. At the expiration of a week, therefore, the apparatus was reapplied with greater care, and so efficiently that he left his bed on the recond day after it application to $8^{\circ}$ on erutches; and from that tines the 
berer tept his bed, but rent daily into the open air, by which means he soon regained his strength. The necrosed bone came sway in nineteen pieces; the wound then healed, and osseous union of the healthy bone simultaneously took place, giving him a shortened and deformed, but useful limb.

I saw this man a fow days since: he is able to perform a day's work, and, by wearing a thick soled boot, can walk well. He fully attributes the salvation of his limb to the treatment by the apparatus, which, I am inclined to think, if it had been adopted immedintely after the scoidont, rould have resulted in obviating the deformity of tho limb, and shortened the process of cure from five months to a many weeks, as the parallel case of Tustin (vide page 348) warrants me in asserting.

Thirty well authenticated cases of fracture, the reports of which have been taken indiscriminately from amongot many others treated in a like manner at the Queen's Hos pital, have been published in this JoURNAL; and thewe I now propose to draw up in a tabular form.

Tabular View of Cases of Fracture treated by the Starched Apparatus in Queen's Hospital, Birmingham.

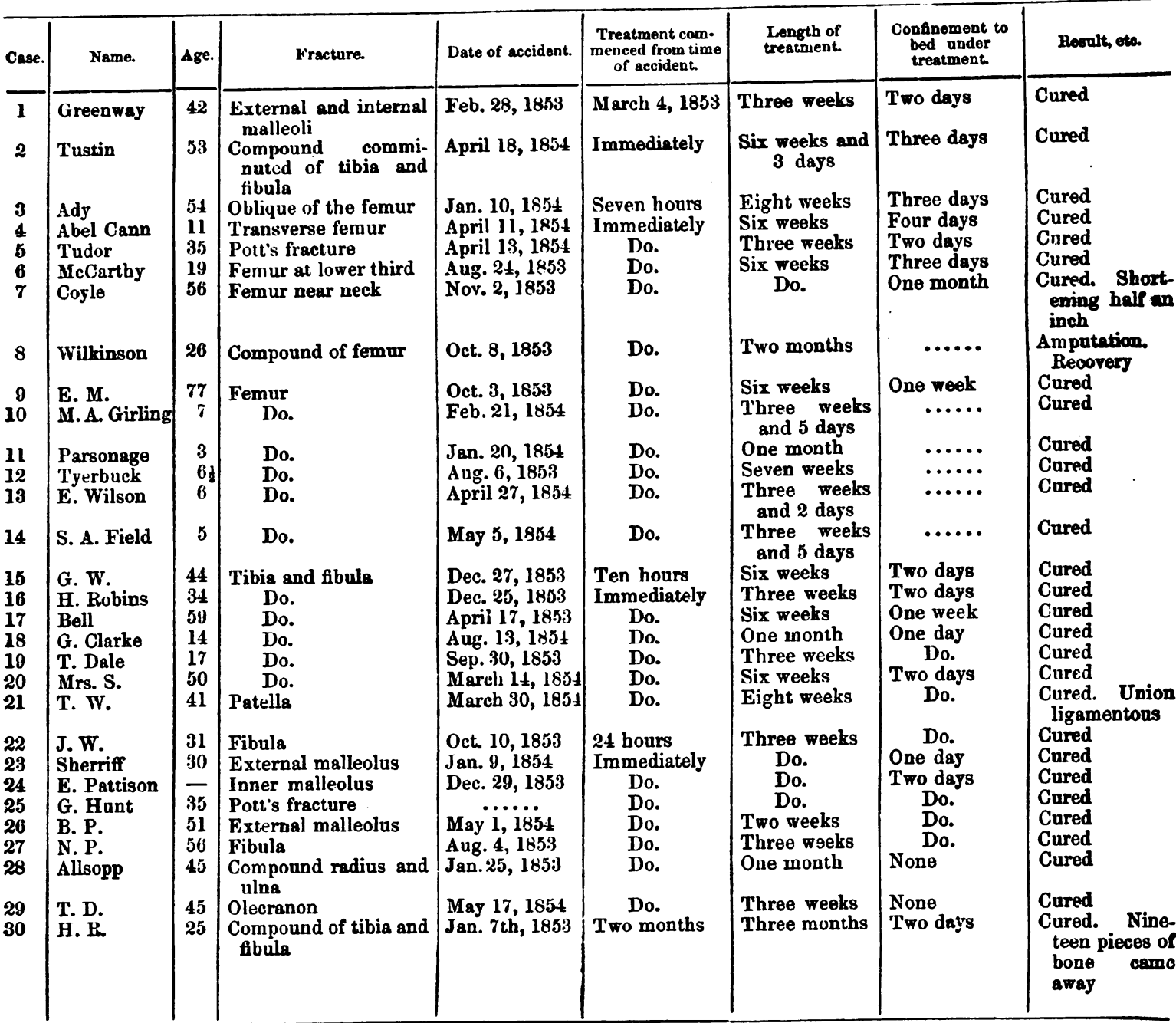

REMarks. In the above table, it will be seen that the ages vary from early childhood to extreme old age; from which it may be inferred that the method is adapted for any age; indeed, I have applied the apparatus in treating a broken thigh, to a child aged sixteen months, and for the same injury to a woman above 80 .

Under the head of Fracture in the table, it will be seen that the femur was the seat of injury in eleren cases; the tibia and fibula together, in eight; the fibula only, in four; the malleoli, either singly or together, in four; the patella, in one; the olecranon, in one; and the radius and ulna, in one. The bones of the lower extremities sustained the injury in every case but two, which may be accounted for from my not taking notes of cases which did not require admission into the hospital; and fractures occurring to the bones of the upper extremity generally do not; yet I have emHis ad the apperatus in treating fracture of the aren and forearm as often as of the leg and thigh, and can as strongty recommend it in the one as the other.

It will be observed that, in the majority of caces, the treatment was commenced immediately after the reeeipt of injury, which may be called the time of election; neither inflammation nor swelling have supervened, and rarely if ever take place after the apparatus has been applied. When, however, several hours or even days have elapeed since the accident, and the limb, in the absence of troat ment, shall have become swollen and inflamed, the application of the apparatus is usually followed by the subaidence of both these conditions.

The length of treatmeat in the above cases does not indicate the period of perfect union in every instance; the ap paratus being worn beyond that time, for the more complete consolidation of the fagments. Judging, howerer, from these and other ases aimilarty treated, union of the 
Prom bone tates place in the following order; namely, the fernur, in six weeks; the tibis and fibule, in four; the fbuli or tibis only, in two to three; the malleoli, in about the ame time; the humerus, in four; and the bones of the forearm, either singly or together, in about three. These remarks refer to solution of continuity of the bone in the adult healthy subject; in childhood, the fragments unite much sooner; while old age, pregnancy, mercurialism, and cachectic states of the system, impede if not altogether suspend union.

Confinement to bed is perhaps the most irksome condition required of the patient under treatment for fracture of a bone of the lower extremity, not to mention the impairment of health it induces. Reference to the above table proves that this may be limited to two or three days, excepting while the fracture is complicated with injury to other parts of the body; and even then the patient may, in most cases, be placed upon a couch during the day.

The results are almost uniformly successful, the bones having united without shortening, and without deformity, in all the cases but three. Of these, one was a very severe compound fracture of the thigh, occurring to a man of weak constitution, which terminated in amputation of the limb ; another was fracture of the femur close to the trochanter, and accompanied with severe contusions of the whole side of the body, in which case a cure was effected with half an inch of shortening; in the third and last, the injury, a compound fracture of the leg, had existed ten weeks before the apparatus was applied; and by this time necrosis of the bone had taken place, and the limb was greatly deformed: the modern method was only adopted, therefore, to save the limb; and in this it succeeded.

In concluding these remarks, I may observe, that every case of fracture which required mechanical aid during the time I was Resident Surgeon at the Queen's Hospital, a period of one year and nine months, was treated by the modern method here recommended, and with equally good results. I must not, therefore, omit to express my acknowledgments to the surgeons of that institution, Mr. Sands Cox, Mr. G. B. Knowles, and Mr. Langston Parker, for having permitted me to make such an extended trial of this plan.

Birmingham, Lugust 1855.

\section{OBSERVATIONS ON THE CORONER'S COUR'T, ON A CASE OF ABSCESS OF THE BRAIN, AND ON THE ADMINISTRATION OF CHLOROFORM. \\ By GEORGF BOTTOMLEY, Esq.}

[This paper, written for the Annual Meeting of the Provincial Association at York, but not read for want of time, is now published by request of the meeting.]

I. THE CORONER'S COURT.

I BEG to call your attention to a most important portion of the medical policy of this country, I allude to Coroners' Courts. In most of the medical periodicals will be found letters from medical practitioners, complaining of the very unsatisfactory and unscientific mode of conducting coroners' inquests, which, in my opinion, arises from the total absence of all knowledge on the part of the non-medical coroner of physiology, and pathology; also ignorance of the effect and symptoms of the various poisons upon the human frame; and in the country districts the jury frequently are composed of men unfit for such a duty. The subject is one that acts most injuriously upon the public at large, and which can only be remedied by the active interference of the medical profession; I therefore consider it our duty to use the means we have in our possession, to correct the evil. Inquests very frequently take place, without any medical evidence, in many cases, where medical testimony only could have elucidated the real cause of death. In such cases the fault li es with the coroners, who (their accounts have to be submitted to the county magistrates), consequently are very desirous of curtailing their expenses, with a deaire to gain their approbation.

By the waj of exemplification, I will relate the result of fer inquests that have come to my knowledge.

When the Brighton railway was under formation, I attended the men professionally. Many of them were of the lowest and most depraved characters. It so happened that two of them paid their attentions to a young servant girl; they quarrelled, and both of them shortly afterwards disappeared. This occurrence took place some short time before harvest. A public foot-path ran through a wheat field in the neighbourhood of their work; and when the wheat was cut, a body was discovered a short distance from the path, the head completely severed; it was recognised as being one of the men that had so suddenly disappeared. At the inquest no searching investigation took place that could have led to the very sapient verdict in that case, which was, that the deceased destroyed himself by cutting off his own head.

Another case was that of a tramp, an old man residing at a common lodging-house. He laboured under asthma; his cough annoyed his fellow-lodgers; they abused and illused the old man. One morning he was found dead, in a sitting posture, against the wall of his bed-room. The verdict in this case was that he died of a fit. From the information I subsequently obtained, I have reason to believe the man had been murdered.

I will now trouble you with one more case, which I will give you as briefly as possible, merely placing before you a plain statement of facts, as follows-that a poor family who resided a few miles from Croydon, consisting of husband, wife, and four children, the youngest at the breast. The man and woman, and the three eldest children, all died in the short space of nine days. There was an inquest, which was adjourned for the purpose of making a post mortem examination. The verdict in this case was death from natural causes, accelerated by typhoid fever; but from the medical evidence I was led to suspect that death was caused by arsenical poisoning. I wrote to the coroner my suspicion, and requested an exhumation of the bodies, for the purpose of submitting their contents to an analytical test by Dr. Taylor, which was refused, the coroner stating he was perfectly satisfied, and he had no funds for the purpose. I then wrote to Lord Palmerston, who was at that time Home Secretary. He wrote to the coroner, requesting him to have one of the bodies exhumed, for the purpose of submitting its contents to an analytical test by Dr. Taylor. The result was that comparatively the liver contained a large quantity of arsenic; in consequence of which the inquest was again opened to hear the result of the analysis, and then a verdict was returned of death by poison (arsenic). From an interview I had with Lord Palmerston upon the subject, I had every reason to believe that he would, had he not been at that time so much engaged in the war question, have made very considerable alterations in the law relating to Coroners' Courts; making them useful, instead of worse than useless tribunals.

I therefore have reason to expect that upon proper representation being made to Government, from the medical profession, the desired object would be attained.

II. CASE OF ABSCESS OF THE RRAIN.

The following case I deem will prove interesting from its pathological character.

A gentleman, aged 43, spent nearly twenty years in Australia, many years of the time on the banks of a lake, which was supposed by his medical attendant to have occasioned a very severe neuralgic affection of the left side of the head and face, which he suffered from for upwards of four years, and not yielding to the usual remedies, he was advised by his medical attendant to come to England for change of air and climate; and, after a short residence in this country, he very much improved, and believed himself to be getting quite well. He was a fine, tall, remarkably well proportioned, and otherwise healthy man, possessing superior mental powers. He continued improving till tho 